\title{
HUBUNGAN AKTIVITAS FISIK DENGAN KUALITAS TIDUR PADA PASIEN DIABETES MELITUS TIPE 2 DI WILAYAH KERJA PUSKESMAS II DENPASAR BARAT
}

\author{
Komang Hadpani ${ }^{1}$, Desak Made Widyanthari ${ }^{2}$, Made Oka Ari Kamayani ${ }^{3}$ \\ ${ }^{123}$ Program Studi Sarjana Keperawatan dan Profesi Ners Fakultas Kedokteran Universitas Udayana \\ Email: komanghadpani@gmail.com
}

\begin{abstract}
ABSTRAK
Diabetes Melitus atau DM ialah ketidakmampuan fungsi pankreas dalam menghasilkan insulin yang cukup. Keadaan ini sering mengakibatkan seseorang mengalami masalah dalam tidurnya sehingga kualitas tidurnya memburuk. Salah satu upaya peningkatan kualitas tidur adalah dengan melakukan aktivitas fisik. Tujuan penelitian ini adalah untuk mengetahui hubungan aktivitas fisik dengan kualitas tidur pada pasien DM tipe 2 di Wilayah Kerja Puskesmas II Denpasar Barat. Jenis penelitian ini adalah deskriptif korelasional dengan rancangan cross sectional. Sampel sebanyak 30 orang menggunakan teknik purposive sampling. Pengumpulan data menggunakan Intemational Physical Activity Questionnare dan Pittsburgh Sleep Quality Indeks. Hasil uji korelasi Spearman Rank menunjukkan ada hubungan ( $\mathrm{p}=0,01 ; r=0,817)$, yang dapat diartikan semakin rendah aktivitas yang dilakukan maka kualitas tidur semakin buruk. Diharapkan penelitian ini dapat dijadikan pedoman dalam memperhatikan aktivitas fisik sehari-hari guna meningkatkan kualitas tidur.
\end{abstract}

Kata kunci: Aktivitas Fisik, Diabetes Melitus, Kualitas Tidur

\begin{abstract}
Diabetes Mellitus or DM is not capable fungsional mecanishm pancreas to produce an enough insulin. Efect of this situasion is difficult to sleep and poor sleep quality. Physical activities are one of many efforts which can increasing sleep quality. This studi is aimed to determine the correlation between physical activities and sleep quality among patients with type 2 diabetes at wilayah kerja Puskesmas II Denpasar Barat. This study is a descriptive correctional with cross sectional study and used a purposive sampling as techniques sampling. Thirty respondents were chosen as sample of this study. Intemational Physical Activity Questionnare and Pittsburgh Sleep Quality Indeks Questionnare are used. The result of the SpearmanRank's correlation test showed that are positive relation $(r=0.817$; $\mathrm{p}=0.01)$. it correlation means the lower physical activity that patient had, makes them have poor sleep quality. The result of this study are expected to be used as a guide to observing daily physical activities to increas sleep quality.
\end{abstract}

Keyword : Physical Activities, Diabetes Mellitus, Sleep Quality 


\section{PENDAHULUAN}

Diabetes Mellitus (DM) ialah ketidakmampuan pankreas dalam menghasilkan insulin yang cukup. (Amarican Diabetes Assosiation, 2018). Prevalensi menunjukkan masih tinggi angka kejadian akibat DM pada usia dewasa. (International Diabetes Federation, 2017). Indonesia menempati peringkat enam tertinggi di dunia. Data tersebut diperkuat kembali dengan hasil catatan Dinas Kesehatan Provinsi Bali tahun 2018 bahwa saat ini Kota Denpasar merupakan kota dengan jumlah pasien DM tertinggi di Bali. Tingginya angka kejadian DM akan meningkatkan jumlah mortilitas pada DM akibat komplikasi.

Pencegahan atau pengurangan terjadinya komplikasi, dapat dilakukan dengan upaya pengelolaan DM tiap 2. Salah satunya yaitu aktivitas fisik (PARKENI, 2015). Penelitian sebelumnya menunjukkan bahwa pasien DM tiap 2 masih melakukan sedentary lifestlye (Dolongseda, Massie dan Bataha, 2017; Nuryanti dan Adriani, 2017).

Aktivitas fisik secara umum juga dapat memengaruhi waktu tidur malam, khususnya pada tahap tidur REM dan NREM (Potter and Perry, 2005). Beberapa peneliti sebelumnya menunjukkan bahwa olahraga dapat meningkatkan kualitas tidur pada kelompok DM tiap 2 (Mendelson et al., 2015; Ebrahini, Nejad dan Pordanjani, 2017)

Pasien DM tipe 2 sering mengalami gangguan tidur sehingga memperburuk kualitas tidur (Khandelwal, Dutta, Chittawar dan Kalra, 2017; Sakamoto et al., 2018). Gangguan tidur yang sering terjadi yaitu, ketidaknyamanan atau nyeri pada malam hari dan nokturia (Lecube et al., 2016). Hal ini dapat mengakibatkan meningkatnya frekuensi terbangun, sulit tidur kembali dan ketidakpuasan tidur sehingga memperburuk kualitas tidur (Surani, Brito, Asif and Ghamande, 2015).

Studi pendahuluan pada Puskesmas II Denpasar Barat, menunjukkan bahwa dari 10 pasien yang diwawancarai diketahui bahwa sebagian besar memiliki gangguan tidur dan kurang aktif dalam berolahraga. Berdasarkan hal tersebut peneliti ingin meneliti lebih lanjut hubungan aktivitas fisik dengan kualitas tidur pada pasien DM tipe 2 di wilayah kerja puskesmas II Denpasar Barat.

\section{METODE PENELITIAN}

Jenis penelitian ini adalah deskriptif korelasional dengan rancangan cross-sectional. Uji statistik parametri yang digunakan adalah Spearman Rank. Sebanyak 30 orang dari seluruh pasien yang berkunjung ke puskesmas bersedia menjadi responden yang memenuhi kriteria inklusi dan eksklusi. Instrumen pengumpulan data yang digunakan yaitu kuesioner IPAQ dan PSQI. Pengumpulan data dilakukan pada tanggal 01-30 Mei 2019 di Puskesmas II Denpasar Barat. Data yang dikumpulkan oleh peneliti dibantu dengan satu orang Enumerator. Setelah mendapatkan ijin penelitian, selanjutnya peneliti melakukan pengumpulan data. Penelitian ini telah mendapatkan kelayakan etik berdasarkan Komisi Etik Fakultas Kedokteran Udayana 1482/UN14.2.2.VII.14/LP/2019. 


\section{HASIL PENELITIAN}

Berdasarkan tabel 1 hasil SMA/SMK sebesar 33,3\%, distribusi frekuensi mengenai Wiraswasta sebesar 33,3\%, GDS $>200 \mathrm{mg} / \mathrm{dl}$ sebesar $60,0 \%$, aktivitas fisik sedang sebesar $56,7 \%$ dan kualitas tidur buruk sebesar $66,7 \%$. sebagian besar DM tipe 2 berusia 56 60 tahun sebesar $46,7 \%$, perempuan sebesar 53,3\%, tingkat pendidikan

Tabel 1 Gambaran Demografis Pasien DM Tipe 2 Di Wilayah Kerja Puskesmas II Denpasar Barat tahun $2019(n=30)$

\begin{tabular}{|c|c|c|}
\hline Karakteristik Responden & Frekuensi (n) & Persentase $(\%)$ \\
\hline \multicolumn{3}{|l|}{ Usia } \\
\hline $36-45$ tahun & 2 & 6,6 \\
\hline 46-55 tahun & 8 & 26,7 \\
\hline 56-65 tahun & 14 & 46,7 \\
\hline$>65$ tahun & 6 & 20,0 \\
\hline Jumlah & 30 & 100,0 \\
\hline \multicolumn{3}{|l|}{ Jenis Kelamin } \\
\hline Laki-laki & 14 & 46,7 \\
\hline Perempuan & 16 & 53,3 \\
\hline Jumlah & 30 & 100,0 \\
\hline \multicolumn{3}{|l|}{ Pendidikan Terakhir } \\
\hline Tidak sekolah atau tidak tamat SD & 4 & 13,3 \\
\hline SD & 9 & 30,0 \\
\hline SMP & 4 & 13,3 \\
\hline SMA/SMK & 10 & 33,4 \\
\hline Perguruan tinggi & 3 & 10,0 \\
\hline Jumlah & 30 & 100,0 \\
\hline \multicolumn{3}{|l|}{ Pekerjaan } \\
\hline Tidak bekerja & 9 & 30,0 \\
\hline Wiraswasta / Pedagang & 10 & 33,3 \\
\hline PNS / Pegawai Swasta & 5 & 16,7 \\
\hline IRT & 6 & 20,0 \\
\hline Jumlah & 30 & 100,0 \\
\hline \multicolumn{3}{|l|}{ GDS } \\
\hline$<200 \mathrm{mg} / \mathrm{dl}$ & 12 & 40,0 \\
\hline$\geq 200 \mathrm{mg} / \mathrm{dl}$ & 18 & 60,0 \\
\hline Jumlah & 30 & 100,0 \\
\hline \multicolumn{3}{|l|}{ Aktivitas Fisik } \\
\hline Aktivitas Rendah & 6 & 20,0 \\
\hline Aktivitas Sedang & 17 & 56,7 \\
\hline Aktivitas Tinggi & 7 & 23,3 \\
\hline Jumlah & 30 & 100,0 \\
\hline \multicolumn{3}{|l|}{ Kualitas Tidur } \\
\hline Kualitas Tidur Buruk (6-21) & 20 & 66,7 \\
\hline Kualitas Tidur Baik (0-5) & 10 & 33,3 \\
\hline Jumlah & 30 & 100,0 \\
\hline
\end{tabular}


Berdasarkan tabel 2 hasil menunjukkan bahwa ada hubungan positif aktivitas fisik dengan kualitas tidur pada pasien DM tipe 2 di Wilayah Kerja Puskesmas II
Denpasar Barat $(\mathrm{p}<0,001 ; \mathrm{r}=0,817)$. Sehingga semakin rendah tingkat aktivitas fisik maka semakin buruk kualitas tidur pada pasien DM tipe 2 .

Tabel 2 Hubungan Aktivitas Fisik dengan Kualitas Tidur pada Pasien DM tipe

\begin{tabular}{ccc}
\hline Variabel & r & p value \\
\hline Aktivitas Fisik dan Kualitas Tidur & 0,817 & 0,001
\end{tabular}

\section{PEMBAHASAN}

Peningkatan glukosa dalam tubuh sering diiringi dengan kualitas tidur yang menurun pada pasien DM tipe 2 . Keadaan ini terjadi akibat deuresis osmosis. Ketika kadar gula dalam darah melebihi ambang batas ginjal, kondisi tersebut dapat mengakibatkan meningkatnya frekuensi terbangun untuk ke kamar mandi, sulit tidur kembali dan ketidakpuasan tidur sehingga menurunkan kualitas tidur pada pasien DM tipe 2 (Surani,Brito, Asif and Ghamande, 2015).

Peningkatan gula darah juga mampu menimbulkan gangguan tidur lain seperti nyeri neuropati. Keluhan nyeri ini berupa rasa kesemutan, tertusuk, dan rasa terbakar yang sering terjadi pada ekstremitas bawah saat akan memulai tidur. Sehingga seseorang membutuhkan waktu lebih banyak untuk tertidur (Sakamoto, et al., 2018)

Pengaturan gula darah pada DM tipe 2 dapat dilakukan dengan melakukan aktivitas fisik. Kontraksi otot selama melakukan aktivitas fisik dapat meningkatkan serapan gula darah untuk melengkapi glikogenolisis intramuskuler. (Colberg et al., 2010). Sensitivitas reseptor insulin dapat meningkat ketika seseorang melakukan aktivitas fisik sehingga dapat membantu proses metabolisme pengubahan glukosa menjadi energi. Kondisi tersebut yang akan memengaruhi kadar gula darah pada pasien DM tipe 2 (Ilyas, 2011)

Aktivitas fisik yang tepat mampu memberikan dampak positif bagi pasien DM tipe 2. Penelitian sebelumnya merekomendasikan latihan aerobik seperti bersepeda, berjalan kaki, berenang dan melakukan pekerjaan rumah secara teratur selama 90-150 menit dengan frekuensi sedikitnya 3 hari dalam seminggu dan jarak latihan tidak lebih dari 2 hari, mampu meningkatkan kontrol glikemi (Sigal et al., 2013).

Peningkatan aktivitas fisik yang dilakukan dapat memperbaiki kualitas tidur. Dalam menyeimbangkan energi yang telah dikeluarkan, keletihan setelah melakukan aktivitas fisik yang tinggi mengakibatkan seseorang membutuhkan waktu tidur. Hal tersebut dapat mempercepat tahap tidur NREM (Baso, Langi dan Sekeon, 2019). Latihan fisik juga mampu meningkatkan kualitas tidur seseorang. Latihan aerobik dengan intensitas sedang mampu meningkatkan kualitas tidur pada orang dewasa (Erlacher, Daniel and Schredi, 2015; Kamrani, Syams, Dehkordi dan Mohajer, 2014). 
Hasil penelitian ini menunjukkan terdapat hubungan aktivitas fisik dengan kualitas tidur pada pasien DM tipe 2 di Wilayah Kerja Puskesmas II Denpasar Barat. Hal ini didukung oleh hasil penelitian Harceu and Morgan (2018) yang menunjukkan aktivitas fisik rendah dapat mengakibatkan seseorang mengalami masalah dalam mengawali, mempertahankan atau bangun di pagi hari dan mengantuk disiang hari.

Pada kelompok DM tipe 2 aktivitas fisik juga mampu meningkatkan kualitas tidur. Intervensi olahraga dan diet serta yoga mampu meningkatkan kualitas tidur dan menurunkan gangguan tidur. Hal ini disebabkan dengan yoga dapat merangsang produksi endorfin dan memperkuat perasaan bahagia di siang hari dan meningkatkan kualitas tidur di malam hari (Nam, Stewart and Dobrosielski, 2016; Ebrahimi, Nejad and Pordanjani, 2017). Sehingga perlu upaya peningkatan aktivitas fisik yang dilakukan pasien DM tipe 2 dalam memperbaiki kualitas tidur.

\section{SIMPULAN DAN SARAN}

Hasil penelitian ini menunjukkan bahwa sebagian besar pasien DM tipe 2 memiliki aktivitas fisik sedang, kualitas tidur buruk dan ada hubungan antara aktivitas fisik dengan kualitas tidur pada pasien DM tipe 2 di Wilayah Kerja Puskesmas Il Denpasar Barat dengan kuat hubungan sangat kuat dan bermakna positif yang artinya semakin rendah aktivitas fisik yang dilakukan maka kualitas tidur pada pasien DM tipe 2 akan semakin buruk..

Berdasarkan hasil penelitian ini, diharapkan peneliti selanjutnya dapat melakukan penelitian multivariat dengan variabel lainnya seperti usia, jenis kelamin, pekerjaan, pengetahuan, kadar gula, dan IMT.

\section{DAFTAR PUSTAKA}

American Diabetes Assosiation (ADA). (2018). Standards of medical care in diabetes. Diakses dari: http://care.diabetesjournals.org (diakses pada 06 Januari 2019)

Baso, M. C., Langi, F. L., \& Sekeon, S. A. (2019). Hubungan antara aktivitas fisik dengan kualitas tidur pada remaja di SMA negeri 9 Manado. Kesmas, 7(5). Diakses dari: http: //www ejournal.unsrat.ac.id.

Colberg, S. R., Sigal, R. J., Fernhall, B., Regensteiner, J. G., Blissmer, B. J., Rubin, R. R., Taber, L. C., Albright, A. L., and Braun. B. (2010). Exercise and type 2 diabetes: the american college of sports medicine and the american diabetes association: joint position statement executive summary. Diabetes care. 33(12), 2692-2696. doi: $10.2337 / \mathrm{dc} 10-9990$

Dolongseda, F. V., Massie, G., \& Bataha, Y. (2017). Hubungan pola aktivitas fisik dan pola makan dengan kadar gula darah pada pasien diabetes melitus tipe ii di poli penyakit dalam rumah sakit pancaran kasih gmim manado. Jurnal Keperawatan, 5(1). Diakses dari: https://ejournal.unsrat.ac.id

Ebrahimi, M., Guilan-Nejad, T.N. and Pordanjani, A.F., (2017). Effect of yoga and aerobics exercise on sleep quality in women with Type 2 diabetes: a randomized controlled 
trial. Sleep Science, 10(2), 6872. doi: 10.5935/19840063.20170012

Erlacher, C., Erlacher, D. and Schredl, M., (2015). The effects of exercise on self-rated sleep among adults with chronic sleep complaints. Journal of Sport and Health Science, 4(3), 289298.

http://dx.doi.org/10.1016/j.jshs. 2014.01.001

Hartescu, I., \& Morgan, K. (2019). Regular physical activity and insomnia: An international perspective. Journal of sleep research, 28(2), 1-9. doi: $10.1111 /$ jsr. 12745

Ilyas, E.I., (2011). Olahraga bagi diabetesi dalam: soegondo, s., soewondo, p., subekti, i., editor. Penatalaksaan diabetes melitus terpadu bagi dokter maupun edukator diabetes. Jakarta: Fakultas Kedokteran Universitas Indonesia.

International Diabetes Federation. (2017). IDF diabetes atlas: 8th edition. Diakses dari: http://diabetesatlas.org (diakses pada 07 Oktober 2018).

Kamrani, A. A. A., Shams, A., Dehkordi, P. S., \& Mohajeri, R. (2014). The effect of low and moderate intensity aerobic exercises on sleep quality in men older adults. Pakistan Journal of Medical Sciences, 30(2), $417 . \quad$ doi: http://dx.doi.org/10.12669/pjms .302 .4386

Khandelwal, D., Dutta, D., Chittawar, S. \& Kalra, S., (2017). Sleep disorders in type 2 diabetes. Indian journal of endocrinology and metabolism, 21(5), $\quad$ 758-761. doi: 10.4103/ijem.IJEM_156_1 7

Lecube T., A., Sánchez P., E., Gómez P., F., Abreu, C., Valls M., J., Mestre, O., Romero, O., Martínez G., M.D., Sampol, G., Ciudin, A. and Hernández, C., (2016). Global assessment of the impact of type 2 diabetes on sleep through specific questionnaires. A case-control study. Plos One, 11(6), 1-9. doi: 10.1371/journal.pone.0157579

Mendelson, M., Borowik, A., Michallet, A.S., Perrin, C., Monneret, D., Faure, P., Levy, P., Pépin, J.L., Wuyam, B. \& Flore, P. (2016). Sleep quality, sleep duration and physical activity in obese adolescents: effects of exercise training. Pediatric

obesity, 11(1), 26-32. doi: 10.1111/ijpo. 12015

Nam, S., Stewart, K.J. and Dobrosielski, D.A., (2016). Lifestyle intervention for sleep disturbances among overweight or obese individuals. Behavioral sleep medicine, 14(3), 343-350. doi:10.1080/15402002.2015.10 07992

Nuryanti, L. \& Adriani, M. (2017). Hubungan aktivitas fisik dengan kadar gula darah puasa penderita diabetes mellitus tipe 2. Amerta Nutrition, 1(2), 80-87. doi: 10.2473/amnt.v1i2.2017.

Perkumpulan Endokrinologi Indonesia (PERKENI). (2015). Konsensus: pengelolaan dan pencegahan diabetes melitus tipe 2 di indonesia. Diakses dari: http://genderi.org (diakses pada 06 Januari 2019).

Potter \& Perry. (2005). Buku ajar fundamental keperawatan. 
Edisi 4, Volume 2. Jakarta: EGC.

Sakamoto, R., Yamakawa, T., Takahashi, K., Suzuki, J., Shinoda, M.M., Sakamaki, K., Danno, H., Tsuchiya, H., Waseda, M., Takano, T. \& Minagawa, F., (2018). Association of usual sleep quality and glycemic control in type 2 diabetes in japanese: a cross sectional study. Sleep and food registry in kanagawa (SOREKA). PloS one, 13(1), 114. https://doi.org/10.1371/journal. pone.0191771

Sigal, R.J., Armstrong, M.J., Colby, P., Kenny, G.P., Plotnikoff, R.C., Reichert, S.M. and Riddell, M.C., (2013). Physical activity and diabetes. Can $J$ Diabetes, 37(Suppl 1), 40-44. doi: https://doi.org/10.1016/j.jcj d.2013.01.018

Surani, S., Brito, V., Surani, A., \& Ghamande, S. (2015). Effect of diabetes mellitus on sleep quality. World journal of diabetes, 6(6), $\quad$ 868-873. doi:10.4239/wjd.v6.i6.868 